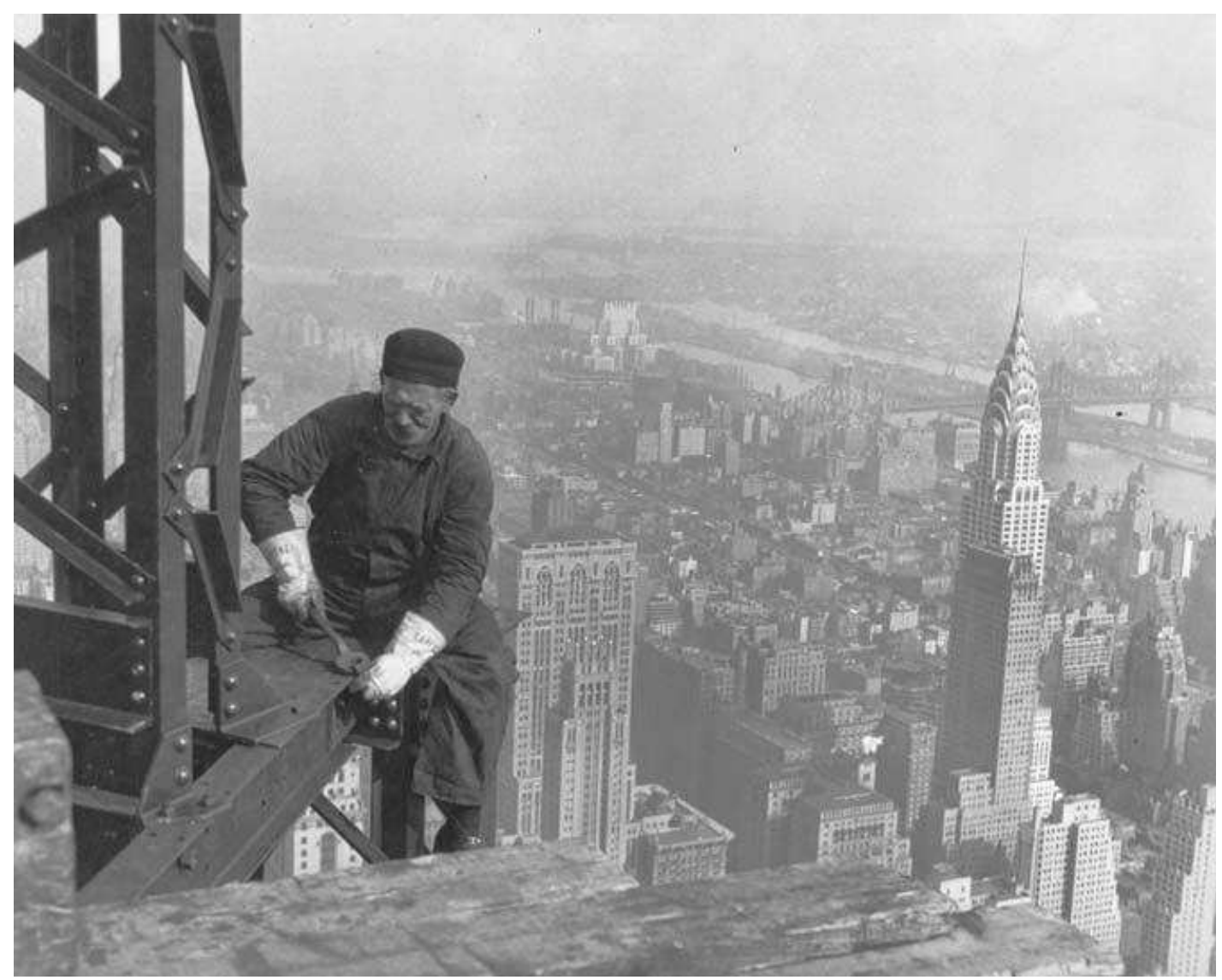

Lewis Hine (1874-1940), Nova lorque, 1930. 


\title{
Expansão e precarização: o mercado de trabalho dos assistentes sociais em Santa Catarina
}

\author{
Expansion and precarization: labor market of social workers \\ in Santa Catarina
}

Maria Teresa dos Santos,* Vania Maria Manfroi*

\begin{abstract}
Resumo: A partir dos resultados da pesquisa "Mercado de trabalho dos assistentes sociais em Santa Catarina", este artigo apresenta uma reflexão acerca das mudanças no "mundo do trabalho" e a realidade das condições de trabalho do assistente social nesse contexto. Os resultados da pesquisa indicam que o exercício profissional do assistente social é impactado pela lógica do mercado expressa nas alterações nos serviços sociais, demandas, sociabilidade, condições e relações de trabalho. As transformações capitalistas em curso repercutiram sobre o cotidiano profissional das assistentes sociais catarinenses. Constata-se que há uma tendência de expansão do mercado de trabalho, porém, com formas precárias de inserção no mercado de trabalho como prestação de serviços, terceirização e contratação de profissionais sem concurso público.
\end{abstract}

Palavras-chave: mercado de trabalho; assistente social; condições de trabalho.

\begin{abstract}
From the results of the research "Labor Market of social workers in Santa Catarina", this article presents a reflection about the changes in the "world of work" and the reality of working conditions of social workers in this context. The research results indicate that the professional practice of the social worker is impacted by market logic expressed in changes in social services, demands, sociability, conditions and labor relations. The capitalist transformations ongoing reverberated on the everyday professional of social workers from Santa Catarina. One can note that there is a trend of expansion of the labor market, however, with precarious forms of insertion in the labor market as service provision, outsourcing and hiring of professionals without public exam.
\end{abstract}

Keywords: labor market; social worker; working conditions.

\footnotetext{
* Assistente social, mestre e doutora em Serviço Social pela Pontifícia Universidade Católica de São Paulo (PUC/SP); professora adjunta da Universidade Federal de Santa Catarina (UFSC). Correspondência: Rua Fernando Ferreira de Melo, 368, AP. 103, Bom Abrigo. Florianópolis/ SC, CEP: 88085-260. E-mail: <mtsantos02@gmail.com>.

** Assistente social, mestre e doutora em Serviço Social pela Pontifícia Universidade Católica de São Paulo (PUC/SP); professora asssociada da Universidade Federal de Santa Catarina (UFSC). Correspondência: Rua Maria Flora Pausewang, 363 ap. 701, Trindade. Florianópolis/ SC, CEP: 88036-800. E-mail: <vaniamanfroi@yahoo.com.br>.
} 


\section{Introdução}

O presente artigo trata de uma reflexão sobre as condições de trabalho dos assistentes sociais, a partir dos resultados da pesquisa "Mercado de Trabalho: formação e exercício profissional dos assistentes sociais de Santa Catarina" desenvolvida no período de 2008 a 2011, com financiamento do Conselho Nacional de Desenvolvimento Científico e Tecnológico (CNPq).

A principal questão que motivou a realização desta pesquisa foi a seguinte: as transformações societárias ocorridas no Brasil pós-1990 afetaram as condições de trabalho -objetivas e subjetivas - dos assistentes sociais? Neste artigo, parte-se dessa questão e busca-se apresentar a realidade das relações e condições de trabalho dos profissionais em exercício profissional no período. Assim, num primeiro momento é apresentada uma breve reflexão teórica acerca das transformações societárias iniciadas no pós1970 que teve como eixo central a financeirização da economia, as transformações na produção e na reprodução da força de trabalho e o papel do Estado nesse contexto.

Em seguida, são apresentados os dados e os principais resultados da pesquisa que combinou uma metodologia quali-quantitativa para a obtenção dos dados. A pesquisa foi organizada de maneira a se aproximar da realidade dos assistentes sociais a partir de algumas microrregiões do estado de Santa Catarina. Na Grande Florianópolis foram aplicados 132 questionários junto aos assistentes sociais inscritos em 2008 no Conselho Regional de Serviço Social (CRESS, 12a . Região). Também foram realizadas três entrevistas com assistentes sociais com o objetivo de resgatar o processo histórico da inserção dos assistentes sociais em Florianópolis e no estado como um todo. Foram realizados grupos focais, com aplicação de um questionário simplificado em Chapecó (que abrange a Região Oeste); em Lages (que abrange as regiões Serrana e Central); em Tubarão (que abrange a Região Norte) e em Itapema (que abrange a Região do Vale do Itajaí). Nos grupos focais contou-se com a participação de assistentes sociais com as seguintes características: dos maiores e menores municípios da região; com formação mais recente e mais antiga; com idades variadas e pertencentes a instituições de diferentes naturezas (públicas e privadas, municipais, estaduais e federais). Também foram realizadas duas entrevistas com profissionais de Chapecó com a finalidade de resgatar o processo histórico da inserção dos profissionais na região.

A análise teórica pautou-se na perspectiva dialética, buscando-se desvendar o caráter de totalidade, contraditório e dinâmico do fenômeno, para se chegar, finalmente, à essência da realidade social. Nessa direção, Pontes afirma que a dialética não é somente uma nova lógica, mas também uma ontologia. Sua estrutura "emerge da relação do sujeito com o modo de ser do objeto - a sociedade burguesa - com seu movimento e suas con- 
tradições". (1995, p. 48). Seguindo seu raciocínio, o autor pontua "que a ontologia marxiana se ancora no primado da economia da determinação homem-natureza" (1995, p. 58). Desse modo, obtém-se o conhecimento da totalidade concreta, essencialmente por meio de "um processo sintético, no qual a razão teórica reproduz, no plano do pensamento, o concreto, como 'concreto pensado' e não mais aquela representação caótica do real". Esse processo "se dá por aproximações sucessivas, ou seja, uma sempre tendencial busca da totalidade" (1995, p. 71,72). Portanto, conhecer o ser social exige um esforço de síntese que vai possibilitar, ao final, conhecer a totalidade social da sociedade burguesa amparada na economia política.

Nesse método, o empírico é o ponto de partida para a análise do real, ele não é o próprio real, pois se torna necessário desvendar as articulações, a gênese, compreender o seu desenvolvimento para poder se aproximar cada vez mais do real. "O método de pesquisa que propicia o conhecimento teórico, partindo da aparência, visa alcançar a essência do objeto". (NETTO, 2009, p. 674). Conforme o mesmo autor, a essência é estrutura e dinâmica, operando sua síntese, "o pesquisador reproduz, no plano ideal, a essência do objeto que investigou" (Ibid, p. 674). Em outras palavras, o pesquisador "tem de se apoderar da matéria, em seus pormenores, de analisar suas diferentes formas de desenvolvimento e permitir a conexão que há entre elas". (NETTO, 2009, p.675).

Cabe destacar aqui a afirmativa de Konder (2009, p.35) que lembra: "para a dialética marxista, o conhecimento é totalizante e a atividade humana, em geral, é um processo de totalização, que nunca alcança uma etapa definitiva e acabada". Neste sentido, os resultados, as análises e as conclusões apresentadas no presente artigo não são capazes de esgotar as múltiplas dimensões do real.

Nesse método, o trabalho é condição de transformação do homem e da natureza, sendo central na vida social. Desta maneira, há um afastamento, de imediato, da tese que afirma que o trabalho teria perdido sua centralidade no mundo contemporâneo. No entanto, há que se qualificar o trabalho a partir da sua inserção na sociedade capitalista, ou seja, a partir da lógica mercantil em que o trabalho é trocado tal qual outra mercadoria e quem regula a sua distribuição é o mercado. "Assim, o valor mercantil não caracteriza coisas, mas um tipo de relações humanas sob as quais as coisas são produzidas" (IAMAMOTO, 2007, p. 60). Então, segundo lamamoto, a sociabilidade capitalista é indissociável do fetichismo da mercadoria.

A autora segue, diferenciando o trabalho em suas formas concreta e abstrata, pois, segundo ela, o trabalho cria um "valor de uso determinado, tendo por suporte um trabalho técnico-material concreto dirigido por produtores individuais mercantis e não pela sociedade" (IAMAMOTO, 2007, p. 61), ou seja, em sua forma concreta, também tem seu caráter abstrato que se caracteriza por sua forma mercantil, pois o trabalho concreto se transforma em trabalho abstrato na sociedade mercantil, pois segundo lamamoto (2007, p. 62) 
Este pressupõe um processo de desresponsabilização (ou equalização do trabalho) que se torna social ao ser socializado e unificado, isto é, ao ser igualado a outras formas de trabalho tornando-se impessoal, despersonalizado, parte da massa total do trabalho homogêneo.

Portanto, ao se analisar o trabalho, faz-se necessário vê-lo sob essa dupla dimensão de trabalho abstrato e trabalho concreto.

O modo de produção capitalista universaliza a relação mercantil (IAMAMOTO, 2007, p. 85) e institui a chamada lei do valor, ou seja, "quando se consolida a produção mercantil, as mercadorias são trocadas conforme a quantidade de trabalho socialmente necessário nelas investido". Desta forma, "a lei do valor passou a regular as relações econômicas quando a produção mercantil, sob o capitalismo, se universalizou". (NETTO; BRAZ, 2006, p.84).

Tendo como objetivo a obtenção da mais-valia, a "tendência a reduzir ao mínimo o preço de custo converte-se na alavanca mais poderosa para a intensificação da força produtiva do trabalho social, que aparece como força produtiva do capital". (IAMAMOTO, 2004, p.13). Em decorrência deste processo há uma ampliação do capital constante em detrimento do capital variável, quando surge uma parcela da população que não pode ser absorvida pelo capital.

Numa perspectiva introdutória é relevante destacar a importância do fundo público para salvar setores da economia nos momentos de crise do capitalismo, havendo, então, uma pressão para que o Estado seja cada vez mais voltado à reprodução do capital. Segundo Salvador (2010a, p. 79), "o fundo público ocupa um papel relevante na articulação das políticas sociais e na sua relação com a reprodução do capital".

Salvador (2010b, p. 606) sinaliza que "a financeirização da riqueza implica em pressão sobre a política social, especialmente as instituições da seguridade social, pois aí está o nicho dos produtos financeiros". Assim, a tendência à contração da universalidade da saúde e educação, por exemplo, tornam-se mais um produto de mercantilização e um mecanismo de "contratendência à queda tendencial da taxa de lucro" (MOTA, 1995). Por isso nas políticas neoliberais é incluída "a transferência da proteção social do âmbito do Estado para o mercado, a liberalização financeira passa pela privatização dos benefícios da seguridade social". (SALVADOR, 2010b, p.606).

Assim, para poder explicar as condições objetivas e subjetivas nas quais os assistentes sociais estão inseridos é importante também demarcar as desregulamentações constitucionais que implicaram em múltiplas perdas de direitos, nas políticas sociais focalistas e na diversificação das formas de contratação de servidores sem concurso público, com a "parceria" com ONGs e a criação de fundações municipais que também passam a gerenciar as políticas nos municípios. Este processo de "contrarreforma" se inicia, de forma mais explícita no governo Fernando Henrique Cardoso (1995 - 1998 e 1999 - 2002), mas tem continuidade nos governos seguintes. 
Ainda vinculado a esse processo, Sabadini (2011, p. 244) desenvolve a hipótese de que a precarização do trabalho tem sido elemento central para a manutenção da atual base capitalista, fundamentada na relação dialética entre capital produtivo e financeiro. Diz o autor:

O crescimento da especulação nos mercados financeiros mundiais, acompanhado de crises financeiras em diversos países do mundo, foi uma tônica nas últimas décadas do século XX e início do século XXI. A liberalização econômica e a reforma do sistema de crédito internacional intensificaram os movimentos especulativos ao redor do mundo, associado as formas pretéritas de exploração e intensificação do trabalho pelas vias da mais-valia absoluta e relativa.

É este o ponto de partida da análise do próximo item, ou seja, como as alterações do trabalho estão vinculadas aos novos movimentos do capital.

\section{Mudanças no capitalismo e no mundo do trabalho}

Há várias interpretações acerca do processo de mudanças que ocorreram a partir da grande crise do capital pós anos 1970 e que puseram fim à chamada "era do ouro" do capitalismo mundial. Nesta seção, far-seá uma breve apresentação sobre os aspectos centrais dessas mudanças e se discutirá, especialmente, sobre o modo como elas repercutiram sobre o mundo do trabalho. Diferentes autores analisam esse processo, alguns o chamam de "acumulação flexível" (HARVEY, 2003), outros de globalização (CANO, 1998; IANNI, 2004), de "mundialização do capital" (CHESNAIS, 1999), de "capital especulativo parasitário" (CARCANHOLO; NAKATANI, 2006) e assim por diante.

Pesquisando esses autores, pode-se verificar que há uma concordância entre eles no sentido de que houve realmente mudanças significativas no pós-1970 e que estas mudanças afetaram todo o globo terrestre, por isto mesmo foram chamadas por alguns de globalização, mundialização ou de uma nova "ordem sociometabólica" (MÉSZÁROS, 2002). Além disto, há outros consensos, principalmente no que diz respeito à mudança no papel do Estado, seja no sentido da ressignificação do Estado-nação (IANNI, 2004) seja no papel de agências multilaterais (Banco Mundial, Fundo Monetário Internacional - FMI) e na criação de blocos econômicos para enfrentar os novos problemas do capitalismo. Ainda no que se refere ao Estado, também há o reconhecimento dos autores de que as políticas buscaram minimizar o Estado a partir do chamado neoliberalismo (ANDERSON, 1995), prevalecendo a ideia de que o mercado deveria se autorregular. Outro aspecto diz respeito às consequências desse processo para os trabalhadores, seja devido às mudanças na gestão da força de trabalho, seja devido às mudanças 
tecnológicas, mas todos reconhecem que houve mudanças significativas no mundo do trabalho, tendo como consequência o desemprego estrutural. Igualmente o papel do sistema financeiro nesse processo é destacado por Chesnais (1999), Carcanholo e Nakatani (2006) e por Harvey (2003).

Chesnais (1999, p.86) afirma que o significado desse processo de mundialização do capital é mais do que uma discussão econômica, pois "diz respeito às formas do domínio social próprio de uma fase histórica, da qual não podemos saber nem quanto tempo durará nem por qual caminho a humanidade dela sairá". Um aspecto central desse processo é a financeirização da economia que se baseia na política monetária "norte-americana combinada de fatores de hierarquização próprios do período da 'mundialização do capital', da interconexão dos mercados de obrigações e do lugar ocupado pelos déficits públicos" (1999, p.98). Este processo "vem pesando cada vez mais na transformação da relação salarial (flexibilidade, precariedade, redução do nível médio dos salários reais)". (1999, p. 99).

Fazendo uma análise da ordem da reprodução sociometabólica do capital, Mészáros entende que o "capital é em última análise, uma forma incontrolável de controle sociometabólico", pois é uma estrutura "[...] 'totalizadora' de controle à qual tudo o mais, inclusive seres humanos, deve se ajustar, e assim provar sua 'viabilidade produtiva', ou parecer, caso não consiga se adaptar". (2002, p.96 - grifos no original).

Em artigo, no qual analisa o desemprego, a precarização e as alternativas para a esquerda, Mészáros (2006, p.27) afirma que "atualmente mesmo os países de capitalismo desenvolvido estão enfrentando o desemprego e o trabalho temporário". Para o autor, "a flexibilidade é um mito, pois se vive uma grande tendência socioeconômica de equalização da taxa de exploração diferencial". (MÉZÁROS, 2006, p.33).

No entendimento de Mota e Amaral, o que verdadeiramente está em jogo é um conjunto de transformações que possibilitem novas condições de acumulação do capital, configurando-se como

um conjunto de mudanças na organização da produção material e nas modalidades de gerência e consumo da força de trabalho, que provocam também [...] impactos nas práticas sociais que intervêm no processo de reprodução material e espiritual da força de trabalho (2000, p. 24).

As transformações em curso na sociedade são referenciadas pelas novas condições de acumulação do capital, ou seja, pela acumulação flexível (HARVEY, 2003). O processo de reestruturação produtiva abarca um conjunto de mudanças sociais, econômicas, políticas e institucionais que transversaliza as relações de trabalho e os modos de vida das classes trabalhadoras, repercutindo também sobre sua vida pessoal e familiar. 
Por outro lado, a acumulação flexível (toyotismo) choca-se com aquele padrão rígido do fordismo, forma pela qual a indústria e o processo de trabalho se consolidaram ao longo do século XX (aproximadamente de 1920 a 1970).

O assistente social, como sujeito profissional, está imerso nas condições postas pelo modo de produção atualmente vigente. lamamoto ressalta:

Ao produzir profundas modificações na divisão social e técnica do trabalho, esse processo, hoje sob hegemonia do capital financeiro, vem mudando o perfil do mercado de trabalho, as funções e atribuições profissionais, alterando as formas consagradas de produção e de gestão do trabalho, introduzindo mudanças nas demandas, requisitos de qualificação e atribuições profissionais. (IAMAMOTO, 2006, p. 109 $-110)$.

É ainda de suma importância que se identifique como se dão essas transformações no mundo do trabalho no setor público (Estado), pois até o momento se discutiu sobre esse processo no âmbito da empresa, sabendo, no entanto, que ele ocorre também na esfera estatal.

\section{A realidade do mercado de trabalho dos assistentes sociais em Santa Catarina}

O mundo laboral sofreu mudanças da forma de gestão da força de trabalho, substituindo o fordismo-taylorismo pela acumulação flexível. Este modelo implicou também na flexibilização das relações e a diversificação de formas de contratação da força do trabalho. Isto desencadeou o desemprego estrutural, a perda dos direitos sociais, além da ampliação dos programas assistenciais focalizados e a desresponsabilização parcial do Estado no enfrentamento à questão social. A pesquisa teve como hipótese a assertiva de que as mudanças ocorridas no mundo do trabalho repercutiram sobre a condição de trabalhador do assistente social catarinense.

Um primeiro dado da pesquisa revela que 75 profissionais num total de 170 possuem um vínculo de estabilidade permitido pela inserção por concurso público, o que significa um percentual de $44 \%$. Outros $27 \%$ dos assistentes sociais estão contratados com carteira assinada e 16\% têm vínculos de trabalho precários (terceirizado, autônomo, prestador de serviços, contrato temporário). Houve também o registro de aposentados $(4 \%)$, comissionados ( $2 \%)$, desempregados $(2 \%)$, outros $(3 \%)$ e $2 \%$ dos pesquisados não responderam. Quanto ao número de desempregados, cabe esclarecer que esta informação pode estar subestimada, uma vez que na Grande Florianópolis só foram pesquisados os profissionais inscritos no CRESS 12 ${ }^{a}$. Região, deixando de fora os assistentes sociais que se formaram e não se inscreveram no Conselho e os que pediram desligamento. Nas de- 
mais regiões os critérios de amostragem foram qualitativos, o que também deixava de fora os assistentes sociais desempregados. Porém, ainda assim, houve a ocorrência de situação de desemprego.

Quanto à natureza da instituição que contrata os assistentes sociais verificou-se que grande parte dos assistentes sociais atua em instituições públicas, tanto na Grande Florianópolis, quanto nas demais regiões de Santa Catarina. Na Grande Florianópolis há a predominância da esfera estadual, seguida da municipal e da federal; já nas demais regiões há uma clara predominância da esfera municipal. Porém, na Grande Florianópolis é relevante o número de profissionais inseridos em organizações sem fins lucrativos o que se explica pelo fato de que parte dos profissionais que atua na esfera municipal é contratada pela via de uma determinada organização não governamental (ONG), configurando-se um processo de terceirização.

Dos 170 profissionais pesquisados nas diferentes regiões do estado, $61 \%$ trabalham em instituições públicas, nos níveis municipal, estadual e federal e 39\% em instituições privadas. Cabe destacar que na região da Grande Florianópolis $29 \%$ dos profissionais são contratados por associação sem fins lucrativos, devendo-se levar em conta que, na maioria dos casos, como já dito, esta contratação significa um processo de terceirização, pois boa parte desses profissionais está atuando efetivamente nas prefeituras. Além disto, nessa região, pelo fato de ser a capital administrativa do estado, há uma forte presença de profissionais inseridos em instituições estaduais e federais.

Nas demais regiões do estado verifica-se que $61 \%$ dos profissionais pesquisados são contratados por instituições públicas, dentre as quais 55\% correspondem às prefeituras municipais e os outros $6 \%$ distribuídos nas esferas estadual e federal, contra $18 \%$ nas empresas e $16 \%$ nas associações sem fins lucrativos.

Quando se cruzam os dados entre a forma de contratação e a natureza da instituição, vê-se que na Grande Florianópolis entre os assistentes sociais que responderam ter uma forma de contratação celetista, $64 \%$ estão nas ONGs e que 6\% responderam atuar na esfera municipal. Daqueles que responderam que a forma de contratação é por meio de contrato temporário, $57 \%$ atuam na instituição pública municipal, contra $7 \%$ no nível federal e $36 \%$ nas ONGs. Dentre os profissionais que responderam que são concursados, o maior índice está, também, no nível municipal, mas de forma equilibrada em relação aos níveis federal e estadual.

A pesquisa captou dados relevantes sobre as condições de trabalho do assistente social que devem ser ressaltados. Muitos profissionais pesquisados apresentam uma situação de estabilidade, sendo efetivos e tendo sua inserção laboral por meio de concurso público, ou seja, possuem um vínculo com estabilidade, o que não significa que as condições reais de trabalho sejam favoráveis, pois é inegável o sucateamento dos serviços públicos, realidade esta que foi reforçada nas respostas dos profissionais sobre as condições de desenvolvimento do trabalho nos setores públicos, seja federal, estadual ou municipal. 
Também há um número significativo de assistentes sociais com carteira assinada, tanto na Grande Florianópolis, quanto nas demais regiões do estado. No entanto, cabe destacar que na Grande Florianópolis, embora não tenha aparecido explicitamente a terceirização como uma realidade, boa parte dos profissionais que têm carteira assinada, efetivamente, são terceirizados à Prefeitura Municipal de Florianópolis por meio de uma ONG. Dentre as modalidades de flexibilização da força de trabalho, apresenta-se a terceirização da prestação de serviços e do trabalho autônomo. Também há o registro de assistentes sociais em cargos comissionados que são temporários durante o período de uma gestão em geral e são vinculados a indicações pessoais dos gestores ou de partidos políticos.

A terceirização de serviços também é uma característica da nova conjuntura do mundo produtivo que expõe os trabalhadores a precárias condições trabalhistas, com elevado nível de insegurança no vínculo empregatício. A fim de exemplificar, registra-se que no estado de Santa Catarina entre 1995 e 2005, houve um aumento expressivo de postos de trabalho terceirizados, inclusive no setor público, conforme apresentado nos dados do Sistema Nacional de Emprego de Santa Catarina (SINE/SC), onde se afirma que "em 1995 os postos de trabalho terceirizados correspondiam a 11,2\% do total de empregos no setor público e passaram para 34\% em 2005". (VIEIRA FILHO, 2006, p. 5).

Destaca-se a informação obtida em uma entrevista realizada na Grande Florianópolis, na qual se comenta a situação que ocorre em nível municipal, partindo-se da ideia de que a estruturação das políticas sociais propostas na Norma Operacional Básica de Recursos Humanos (NOB/RH) talvez possa ajudar a enfrentar a questão do vínculo precário nos municípios, como se vê no trecho aqui transcrito:

Como o Ministério está implementando muitas ações e está fazendo também exigências em termos de contrapartida [...] à $\mathrm{NOB} / \mathrm{RH}$, ela veio justamente compensando essa questão estratégica que é a questão do quadro de pessoal [...] o tempo todo a gente escuta, vê os documentos, a questão do quadro efetivo... e houve assim nos últimos tempos uma inversão, então, têm sido terceirizados muito os serviços [...] a expansão do quadro efetivo ela é pequena em relação ao que é o quadro terceirizado... isso complica muito.[...] Então fica bem complicado a gente dar conta da continuidade do serviço, de qualidade [...] é diferente quando se é técnico efetivo, você tem uma postura, você tem muito mais liberdade de estar se colocando do que alguém que está temporariamente com o vinculo temporário precário. (entrevistada 5).

Completando a análise acima, surgiram nos grupos focais outras informações sobre a precariedade das condições de trabalho, como ilustra o depoimento da assistente social de Chapecó: 
$\mathrm{Na}$ prefeitura, hoje, eu nem sei te dizer exatamente quantos assistentes sociais tem, porque entram assistentes sociais todos os dias, [...] então eu não sei te dizer, em torno de umas 30-40, deve ser mais ou menos por ai hoje na prefeitura, então, através de concurso público, como é o meu caso, e também agora uma nova modalidade que é o teste seletivo, que é uma modalidade temporária, contrato temporário. (participante 1).

A resposta da profissional aponta a precariedade a que estão submetidos os assistentes sociais nas suas relações de trabalho. Um dos desencadeadores desse processo foi a criação de uma fundação municipal para contratação dos profissionais, dado complementado pelo próximo depoimento:

Sobre as condições de trabalho estão entrando algumas assistentes sociais novas, e dessas [...] a maioria é concursada, mas as novas que estão entrando, estão entrando por processo seletivo, contrato temporário. Aí [...] são tratadas diferencialmente e, inclusive, salarialmente, elas ganham $\mathrm{R} \$ 1.200,00$, ganham bem menos e fazem as mesmas coisas que nós, que somos concursadas. Trabalham a mesma quantidade de horas, do mesmo jeito, então a gente assim, em [...] está tendo um problema, eu acho, da questão da gestão, bem sério. Pensando nas condições de trabalho, da valorização. (participante 9).

Assim, pode-se observar que na região de Chapecó há uma tendência a adotar formas de contratação no setor público que não se viabilizam por meio de concursos públicos.

Já na realidade de Lages encontraram-se os seguintes dados: um número equivalente de profissionais estava contratado em instituições municipais e estaduais, duas trabalhavam em ONGs, mas uma estava desempregada. Percebe-se que o tipo de vínculo varia bastante, pois na mesma instituição há assistentes sociais com vínculo estável e outras que são celetistas. Merece destaque ainda o fato de que a única profissional que atua numa ONG, trabalha como prestadora de serviço.

$\mathrm{Na}$ região de Itapema, nota-se a existência de dois assistentes sociais com duplo vínculo em instituições municipais. A maioria dos profissionais está inserida no município (oito dos dez pesquisados), mas também há a presença de um profissional em ONG e um em instituição pública federal. A respeito dos vínculos, percebe-se que a grande maioria (oito) tem vínculo estatutário, um é prestador de serviço e um está em cargo comissionado. Mais uma vez aparece a ONG como espaço em que há a prestação de serviço.

Em Itapema, duas profissionais possuem dois vínculos, porque atuam em dois municípios diferentes. As profissionais justificam a existência de dois vínculos devido ao alto custo de vida nas cidades em que moram, 
além do fato de os salários serem baixos nas prefeituras, havendo, portanto, a necessidade de se fazer essa opção.

Em Tubarão, observa-se que quatro profissionais estão inseridos na esfera pública municipal e três em uma universidade comunitária. Apenas um assistente social possui dois vínculos, sendo um público e o outro privado. Além disto, nota-se que há dois tipos de contratação nas prefeituras municipais: estatutário e celetista.

Raichelis $(2009$, p.383) se utiliza da pesquisa realizada pelo CFESS, que revela que os assistentes sociais "continuam sendo majoritariamente trabalhadores assalariados, principalmente dos organismos governamentais, com ênfase para o campo da seguridade social nas políticas de saúde e assistência social", com redução nos setores federal e estadual e transferência para os municípios.

Esse dado foi confirmado também em nossa pesquisa, pois se constatou que a grande maioria dos profissionais pesquisados está inserida no setor público, ganhando destaque o setor público municipal. De fato, a fragilidade dos vínculos de trabalho, relatados pelos sujeitos da pesquisa em Santa Catarina, encontra eco nas tendências para o mercado de trabalho identificadas por Raichelis (2009):

- subcontratação de serviços individuais dos assistentes sociais para assessorias na prestação de serviços aos governos, autônomo, temporário, por tarefa, em função das novas formas de gestão das políticas sociais;

- habitação social: terceirização, contratação por contratos licitatórios;

- política de assistência social: variadas modalidades de terceirização, pela mediação de empresas, ONGs, contratação de profissionais e na prestação de serviços assistenciais, configurando-se ação indireta do Estado na produção dos serviços públicos;

Foram pesquisados também os salários dos assistentes sociais da Grande Florianópolis e dos grupos focais. Na Grande Florianópolis, 24\% dos pesquisados recebem um salário entre $\mathrm{R} \$ 3.001,00$ e $\mathrm{R} \$$ 5.000,00; $21 \%$ recebem de $R \$ 1.001,00$ a $R \$ 3.000,00 ; 16 \%$ têm salário acima de $\mathrm{R} \$ 5.000,00 ; 12 \%$ ganham de $\mathrm{R} \$ 1.501,00$ a $\mathrm{R} \$ 2$ 000,00; $11 \%$ recebem de $R$ \$ 1.251,00 a R \$ 1.500,00; 8\% não estão inseridos na área de Serviço Social; $6 \%$ recebem de $\mathrm{R} \$ 1.001,00$ a $\mathrm{R} \$ 1.250,00$; e $1 \%$ recebe de $\mathrm{R} \$$ 502,00 a $R \$$ a $1.000,00$.

$\mathrm{Na}$ Região Oeste a pesquisa foi realizada em Chapecó e verificouse a seguinte realidade: oito assistentes sociais recebem entre $R \$ 2.000,00$ e 2.800,00; uma recebe $R \$ 3.600,00$ e outra recebe $R \$ 5.000,00$.

Solicitou-se que os profissionais falassem sobre os seus salários e houve opiniões diferentes. Uma das entrevistadas assim se manifestou: 
O salário é pequeno não é gente? Vamos falar sério. Uma profissão que exige a qualificação que a nossa profissão exige, a seriedade, trabalha também com recursos públicos, que é uma questão séria, a questão da ética, a questão do desgaste emocional, [...], chega em casa, às vezes, leva aquele problema consigo, então são muitos conflitos familiares. Eu acho que o salário está muito aquém do mínimo exigido para uma profissão como a nossa, [...] Dentro da Prefeitura também tem uma briga, vamos dizer assim, uma luta histórica das assistentes sociais, também psicólogos estão junto, que também são mal remunerados, também fonoaudiólogos estão juntos [...]. Recentemente teve um embate, uma luta por melhoria salarial, [...] mas nenhum (resultado). Já na outra gestão, na outra administração, não conseguiram, nessa também não conseguiram, agora tem um outro prefeito, também não conseguiram, [...] Faz uns dez anos essa luta aí, e nesse período a única coisa que conseguiram foi a redução da carga horária, de quarenta para trinta, que seria uma questão provisória, até melhorar o salário. E aí como o salário não melhorou, ficou com essa carga horária, e agora então nós recebemos uma nova ordem que tem que voltar pras quarenta horas com o mesmo salário. Então você imagina assim, o descontentamento está enorme. (participante 1).

Na Região Serrana a pesquisa foi realizada em Lages. A realidade desta região, em termos salariais, é bem diferente. Constatou-se que os salários são bem mais baixos do que em Chapecó. Há salários de R\$ 500,00, porém a profissional não atua na área; assim como oito profissionais recebem entre $R$ \$ 1.000,00 e R\$ 1.600,00 e outras duas cujos salários situam-se entre R\$2.300,00 e R\$3.500,00.

Ao pedir que as participantes se manifestassem sobre os salários, algumas demonstraram, nos seus depoimentos, ter consciência de que esses salários são muito baixos. Em geral, elas atribuem isto às características coronelista e clientelista da cultura política da região, e também à falta de reconhecimento profissional, conforme se observa no próximo depoimento:

Então aqui é um dos salários mais baixos. Esses dias trabalhando em parceria com o NUPS eu fiz uma pesquisa de preço, os valores que se pagam os salários e Lages ficava na segunda cidade. [...] . É um absurdo,uma cidade que deveria ser o polo da distribuição, devia ser o lugar onde se concentra e muitas vezes até que faz trabalhos parceiros com os municípios, ser o que que menos respeita a profissão do serviço social. (participante 18).

Já na Região do Médio Vale do Itajaí a pesquisa foi realizada no município de Itapema e registrou-se que há duas profissionais com salário entre $\mathrm{R} \$ 1.500,00$ e $\mathrm{R} \$ 1.600,00$; duas que recebem entre $\mathrm{R} \$ 3.000,00$ mil e R\$ 3.800,00; duas que recebem entre $R \$ 4.200,00$ e $R \$ 4.300,00$; e uma que recebe $R \$ 6.000,00$. O maior salário é da assistente social que atua em uma instituição pública federal. Há uma grande diferença entre o 
salário da profissional que atua numa instituição pública federal e o salário das demais.

Percebe-se ainda que os salários mais baixos estão nas prefeituras municipais. Uma participante compara o seu salário atual com o do seu trabalho anterior, que era de costureira, e o considera muito ruim. Em seu depoimento, ela conclama as colegas a justificarem o porquê de terem dois empregos:

Eu acho o salário péssimo mesmo, porque eu comparo quando eu era costureira eu ganhava três salários mínimos e hoje eu ganho a mesma coisa e eu fiz uma faculdade, então o salário é muito ruim, eu acho muito ruim o salário, e daí quem tem dois empregos ai, não preciso dizer porque que tem dois empregos, porque o salário é ruim e daí a carga horária (participante 30).

$\mathrm{Na}$ fala seguinte, nota-se que há dificuldade de contratação nas prefeituras devido ao baixo salário:

Nós éramos em doze, a coordenadora brigava pra ampliar a equipe porque tinha uma demanda gigantesca, houve toda uma reformulação, o serviço passou a ser CREAS e agora estamos em quatro com PAIF... um caos absoluto. Não é assim por falta de vontade, porque houve um concurso público, chamaram todas as que tiveram médias. As assistentes sociais não assumem em função até do baixo salário que acontece aqui em Balneário. Também as pessoas que fizeram concurso lá em 2000, [...] já estão com a vida mais ou menos em outro município, têm família pra se mudar pra cá, tem que ser um salário compatível [...]. Foram chamadas sessenta assistentes sociais e hoje o quadro da Secretaria lá de Balneário é de dezenove, de Itajaí. É confuso (risos). Então é bem complicado, faltam todos os profissionais de todos os níveis, não só assistente social, estão pensando em fazer um outro concurso, mas tem outros problemas de nível administrativo [...], houve uma melhora na infra-estrutura, conseguimos computadores que era tão sonhado, não tínhamos computadores e quando trabalhamos lá em Itajaí eu ficava oito horas, mas eu ficava na temporada três horas dentro do (ônibus) Praiana pra chegar em Balneário Camboriú, então assim muito difícil também, e agora eu 'tô' seis lá e seis aqui, que nem tu perguntastes o que afeta no teu pessoal, afeta tudo! A vida da gente, trabalhar 12 horas afeta tudo, é uma opção é, no meu caso temporário, ninguém aguenta (participante 29).

Esta fala expõe o desgaste que significa o duplo vínculo de trabaIho, pois mesmo com a carga horária de 30 horas, são doze horas de trabalho por dia. Outra participante complementa:

[O] salário não é satisfatório pra quem mora em Balneário Camboriú, para quem tem que pagar aluguel, não tem condições e acredito que 
até final do ano que vem vai sair uma proposta de plano de cargos e salários, mas não sei o que vai mudar de valores então não. (participante 26).

Ainda sobre o salário dos profissionais de nível superior verificouse que nem sempre os salários são iguais, como revela o seguinte depoimento: "Itapema não, assistente social ganha menos que o psicólogo da saúde" (participante 30).

Na Região Sul de Santa Catarina, a pesquisa foi realizada em Tubarão e lá também se encontram salários muito baixos, especialmente nas instituições públicas municipais, variando os salários de R\$ 840,00 até R\$ $5.600,00$, predominando, entretanto, aqueles salários entre $\mathrm{R} \$ 1.300$, e $\mathrm{R} \$ 2.000,00^{1}$.

Algumas profissionais se manifestaram acerca dos salários e o consideraram extremamente baixos. Como se pode constatar no próximo depoimento, também se vincula esse nível baixo à falta de reconhecimento da área de assistência social:

E eu particularmente, e nós conversando, atribuindo a diferença exorbitante de salário, porque na verdade nós somos as pobres da assistência social, e as forenses são as que ganham razoavelmente bem ou dentro daquela proposta de piso salarial que o CRESS até indica. (participante $34)$.

Uma profissional chegou a comparar o seu salário com o de uma usuária, como atesta seu depoimento:

Meu caso foi que mudou minha carreira, no meu registro está como Assistente Social, só que o meu salário ficou o que eu já tinha, já estava alcançado o piso e ficou como o piso. [...] A gente vai ter muitas pessoas novas indo morar lá, por que nós não temos mão de obra qualificada, que o município está correndo atrás, mas eu atendi uma moça que trabalha nos serviços gerais no Porto de Imbituba, por seis horas com um salário de $\mathrm{R} \$ 850,00$. Quando eu peguei o contracheque eu disse '- Meu Deus, o que é que eu estou fazendo aqui' por que o problema não é ela ganhar $\mathrm{R} \$ 850,00$, é o assistente social ter um salário de R\$1.200,00. Em Imbituba são R\$ 1.200,00 por quarenta horas, então é muito desigual. (participante 34).

Ainda outra profissional aponta que, além da desmotivação salarial, há a dificuldade de realização do trabalho em si, pois falta autonomia

\footnotetext{
1 Não existe um piso salarial, existem Projetos de Lei na Câmara dos Deputados, conforme informação do sítio eletrônico do CFESS, através do documento "Acompanhamento dos projetos de lei em tramitação na Câmara dos Deputados e no Senado. Disponível em: <http://www.cfess. org.br/arquivos/Acompanhamento-PLs.pdf>. Acesso em: 03 abr. 2011. O que existe é a tabela de honorários, disponível no mesmo sítio eletrônico.
} 
e devido a isto o profissional tem dificuldade de ser transparente com a população:

A profissão do assistente social é muito desvalorizada, [...], a empresa te contrata pra você trabalhar com a família ou com o funcionário, e tu não podes nem ser verdadeira com eles, então a gente acaba omitindo muito, tanto para a pessoa que tu estás atendendo ou trabalhando com aquela pessoa, e também desmotiva pelo salário. (participante 38).

A falta de autonomia, de reconhecimento e valorização profissional foram temas amplamente tratados pelos profissionais no decorrer da pesquisa, porém, não há espaço aqui para detalhar estes temas.

Perguntou-se também aos profissionais da grande Florianópolis se já haviam ficado desempregados na área de Serviço Social e foram obtidas as seguintes respostas: setenta e oito (59\%) responderam que não e cinquenta e quatro $(41 \%)$ responderam afirmativamente.

Para entender melhor essa realidade, solicitou-se que os profissionais que responderam afirmativamente à questão anterior dissessem quantas vezes ficaram desempregados. Encontrou-se o seguinte resultado: quarenta e um profissionais ficaram desempregados uma vez, cinco deles perderam o emprego duas vezes, um respondeu que esteve desempregado três vezes, outro ficou sem emprego cinco vezes, dois responderam que sempre estiveram desempregados, um disse que trabalha em outra área e três não responderam.

Ainda no intento de detalhar mais a informação, solicitou-se que o assistente social respondesse se havia desenvolvido atividades no período em que ficou desempregado na área. Dos cinquenta e quatro profissionais que ficaram desempregados, quarenta e dois $(78 \%)$ desenvolveram outro tipo de atividade.

As assistentes sociais foram indagadas também sobre quais atividades foram desenvolvidas no período de desemprego. Alguns assistentes sociais, inclusive, desenvolveram mais de uma atividade quando ficaram desempregados. Observa-se que foram atividades bem diferenciadas, sendo citadas desde atividades administrativas, capacitações, organizações de eventos, pesquisa, estudo para concurso público, estudo para mestrado, professor, no comércio e outras mais.

Já na realidade de Chapecó, no que se refere à situação no mercado de trabalho, vê-se que, das dez profissionais que participaram da pesquisa, quatro ficaram desempregadas, sendo duas por períodos de dois anos; uma por um período de três meses; e uma por um período de um mês,

Outro dado interessante é que uma profissional que se formou há mais tempo, em 1983, apesar de ter ficado dois anos desempregada, está há treze anos na mesma instituição, o que demonstra uma certa estabi- 
lidade no emprego. Além disso, nota-se que outra profissional que se formou em 2001, também ficou desempregada por dois anos, ao passo que uma terceira profissional que se graduou em 2009, nunca ficou desempregada.

Em Itapema, verifica-se que quatro assistentes sociais ficaram desempregadas, uma por um período de seis dias, outra por cinco meses e duas durante um ano, mas as outras quatro nunca ficaram desempregadas. O que se observa é que todas as profissionais, independentemente do ano de conclusão da graduação, estão nas instituições há pouco tempo, ou seja, entre um mês e três anos e seis meses. Este é, sem dúvida, um dado relevante porque mostra uma inserção bastante recente dos profissionais pesquisados.

Em Tubarão, relativamente ao ano em que se graduaram, há profissionais formados desde os anos 1980 e outros que se formaram mais recentemente. A maioria se formou há mais de vinte anos. Quanto ao tempo de atuação na instituição observa-se que há uma variação: existem profissionais que estão há mais de vinte na mesma instituição, mas também aqueles que estão ali há apenas dois meses. Quanto ao desemprego, três declararam ter ficado desempregados e apenas um manifestou que o desemprego foi opcional.

Como se pode confirmar nas entrevistas abaixo, a partir do processo de descentralização político-administrativa se percebeu o impacto no mercado de trabalho dos assistentes sociais catarinenses:

Com o processo de descentralização e os municípios passando a assumir cada vez mais responsabilidade em relação à gestão das políticas públicas, automaticamente foi ampliando o espaço do campo profissional no município e em relação a isso. (Entrevistada 5).

E aí eu vejo assim: partimos desse processo de municipalização, hoje, a gente tem duas, três, quatro Assistentes Sociais nos municípios pequenos, claro que Chapecó tem um número bem significativo. Acho, por exemplo, Chapecó que está expandindo mais é na área da Assistência Social que é a maior concentração das Assistentes Sociais na prefeitura. (Entrevistada 2).

Para finalizar essa breve apresentação de dados que resultaram do amplo resultado de investigação apresenta-se uma tendência observada na pesquisa que foi o processo de ampliação e interiorização da profissão, ou seja, a ampliação dos postos de trabalho em municípios considerados de médio e pequeno porte, decorrente do processo de municipalização.

Outro aspecto a ser destacado é quanto ao processo de adoecimento profissional, especialmente entre os profissionais da Grande Florianópolis, mas que também apareceu nos grupos focais, desenvolvidos nas diferentes regiões do estado.

Viu-se, na pesquisa, que esse processo tende a se ampliar, porque cresce a demanda de trabalho aos assistentes sociais, que registraram a car- 
ga horária excessiva, a falta de tempo para a vida social e o lazer, as pressões políticas, a falta de autonomia e o reconhecimento profissional, a pressão moral, entre outros fatores.

O crescimento da demanda, aliado à falta de condições de trabalho nas instituições, tem acarretado inúmeros problemas de saúde aos profissionais. Os problemas são de ordem física, tais como dores, hipertensão, cansaço, doenças profissionais e também emocionais, como frustração, desânimo, angústia, ansiedade, insônia, decorrentes das condições de trabalho e da própria precariedade das instituições. Esse crescente adoecimento profissional se deve à insegurança desencadeada pelas alterações, seja no mundo do trabalho, seja nas políticas sociais, decorrentes do neoliberalismo. Como afirma Antunes (1999), as consequências das mudanças no mundo do trabalho afetaram, tanto objetiva quanto subjetivamente, a vida dos trabalhadores.

\section{Considerações Finais}

Em suma, viu-se que as transformações que ocorreram no mundo do trabalho repercutiram sobre o cotidiano profissional das assistentes sociais catarinenses. Há uma tendência de expansão do mercado de trabalho, porém, aparecem formas precárias de inserção no mercado de trabalho por meio da prestação de serviços, terceirização e criação de fundações que contratam profissionais sem concurso público.

Observa-se também uma discrepância entre os salários: quanto mais precário o vínculo, mais baixo é o salário. Percebe-se ainda que precariedade nas contratações ocorre com mais frequência nas prefeituras municipais e nas ONGs. Na região de Lages e Itapema foram observados os mais baixos salários.

O que se pôde notar é que, majoritariamente, os assistentes sociais de Santa Catarina estão inseridos nas instituições públicas, o que segue a tendência nacional. Há uma crescente expansão de vagas nas prefeituras municipais, num primeiro momento, devido ao processo de municipalização e, atualmente, devido à ampliação da assistência social, por meio da implantação do SUAS. Houve, inclusive, uma polêmica acerca do crescimento da área de assistência social no governo Lula e se chegou a chamar este processo de assistencialização das políticas sociais.

Nesta perspectiva, como observaram os participantes dos grupos focais e entrevistados, verifica-se que há uma interiorização da profissão. Isto significa que no caso de Santa Catarina que conta com duzentos e noventa e três municípios, são reais as possibilidades de inserção dos assistentes sociais nessas localidades, reforçando a tendência de ampliação do campo de trabalho profissional. 
No entanto, embora o campo de trabalho dos assistentes sociais esteja em expansão, são gritantes os baixos salários, especialmente nas prefeituras municipais. Além disto, há uma crescente tendência à precarização das relações de trabalho, realidade que se vincula ao ideário neoliberal que preconiza a flexibilização das relações de trabalho, os cortes dos gastos públicos, a focalização das políticas sociais, a mercantilização de serviços rentáveis ao capital, como a saúde e a educação. No Brasil, a Lei de Responsabilidade Fiscal tem o objetivo de criar estratégias para a diminuição dos gastos públicos, congelando salários, incentivando formas mais flexíveis de contratação, dentre outras. Assim, nas áreas de saúde e educação há o tensionamento das relações público e privado e na assistência social há a sempre crescente focalização, sendo o assistente social o profissional que cadastra, seleciona e focaliza.

Outra questão a ser destacada é a de que os dados sobre desemprego dos assistentes sociais ficaram limitados às informações disponíveis pelo CRESS - 12a Região, ou seja, informações dos profissionais que se mantêm inscritos - os que já estão atuando ou aqueles que pretendem (re)ingressar no mercado de trabalho como assistentes sociais. No entanto, ao se indagar, junto aos sujeitos, se já haviam ficado desempregados, viuse que boa parte destes profissionais já teve algum momento de desemprego, tanto na Grande Florianópolis quanto no interior do estado. Esse processo também é decorrente das mudanças no mundo do trabalho. Além disto, há uma rotatividade da força de trabalho, pois o acesso ao mercado de trabalho, por meio dos contratos de prestação de serviços, se dá por um tempo determinado, com o objetivo de não gerar vínculo empregatício. Esta situação é recorrentemente utilizada, por exemplo, no serviço público. No município de Florianópolis há a contratação de profissionais por uma organização não governamental e eles prestam serviços à Prefeitura Municipal, porém, contratados por essa ONG, e em Chapecó se constatou que o mesmo processo ocorre por meio da criação de uma fundação.

Como bem afirma lamamoto (2007), o assistente social é um trabalhador assalariado que vende sua força de trabalho e, que, portanto, desenvolve um trabalho abstrato. Contudo, também pode ser considerado como um trabalho concreto, ao responder às necessidades sociais, sendo um trabalho útil.

Assim, é neste cenário que se pode afirmar que houve a ampliação de postos de trabalho para os assistentes sociais em Santa Catarina, especialmente no âmbito público municipal, entretanto, com ínfimos salários e com tendência à precarização. 


\section{ReVista all pavtg}

\} EXPANSÃO E PRECARIZAÇÃO: O MERCADO DE TRABALHO - SANTOS, M. T.; MANFROI, V. M. \}

\section{Referências}

ANDERSON, P. Balanço do neoliberalismo. In: SADER, E.; GENTILLI, P. Pós-neoliberalismo: as políticas sociais e o Estado Democrático. Rio de Janeiro: Paz e Terra, 1995.

ANTUNES, R. Adeus ao trabalho? Ensaio sobre as metamorfoses e a centralidade do mundo do trabalho. 6a. ed. São Paulo: Cortez, 1999.

CANO, W.Introdução à economia: uma abordagem crítica. São Paulo: UNESP, 1998.

CARCANHOLO, R.; NAKATANI, P. Capitalismo especulativo e alternativas. XI Encontro nacional de economia política. Vitória, ES. 2006. Disponível em: <http://www.sep.org.br/artigos? conference=11 \&title=\&author=nakatani>. Acesso em 17 fev.2011.

CFESS. Acompanhamento dos projetos de lei em tramitação na Câmara dos Deputados e no Senado. Disponível em: <http://www.cfess.org.br/arquivos/Acompanhamento-PLs.pdf>. Acesso em: 03 abr. 2011.

Tabela referencial de honorários do serviço social. Disponível em: <http://www.cfess.org.br/legislacao_tabela.php>. Acesso em: 03 abr. 2011. CHESNAIS, F. Um programa de ruptura com o neoliberalismo. In: A crise dos paradigmas em ciências sociais e os desafios para o século XXI. Rio de Janeiro: Contraponto, 1999.

HARVEY, D. Condição pós-moderna: uma pesquisa sobre as origens da mudança cultural. 12a. ed. São Paulo: Loyola, 2003.

IAMAMOTO, M. V. Serviço Social em tempo de capital fetiche: capital financeiro, trabalho e questão social. 2a.ed. São Paulo: Cortez, 2007.

. O serviço social na contemporaneidade: trabalho e formação profissional. 10a. ed. São Paulo: Cortez, 2006.

A questão social no capitalismo. In: Temporalis. n. 3. Brasília: ABEPSS, 2004.

IANNI, O. Teorias da globalização. 12a. ed. Rio de Janeiro: Civilização Brasileira, 2004.

MÉSZÁROS, I. Desemprego e precarização: um grande desafio para a esquerda. In: ANTUNES, R. (Org.). Riqueza e miséria do trabalho no Brasil. São Paulo: Boitempo, 2006.

. Para além do capital. São Paulo: Boitempo, 2002.

MOTA, A.E. Cultura da crise e seguridade: um estudo sobre as tendências da previdência e da assistência social brasileira nos anos 80 e 90. São Paulo: Cortez, 1995. 


\section{Revistg ell paUtg}

\} EXPANSÃO E PRECARIZAÇÃO: O MERCADO DE TRABALHO - SANTOS, M. T.; MANFROI, V. M. \}

MOTA, A.E.; AMARAL, A. Reestruturação do capital, fragmentação do trabalho e Serviço Social. In: MOTA, A.E. (Org.). A nova fábrica de consensos: ensaios sobre a reestruturação empresarial, o trabalho e as demandas ao Serviço Social. 2a. ed. São Paulo: Cortez, 2000.

NETTO, J. P. Introdução ao método na teoria social. In: CFESS/ABEPSS Serviço Social: direitos sociais e competências profissionais. Brasília: CFESS/ABEPSS, UnB-CEAD, 2009.

Cortez, 2006.

BRAZ, M. Economia política: uma introdução crítica. São Paulo:

PONTES, R. N. Mediação e serviço social: um estudo preliminar sobre a categoria teórica e sua apropriação pelo Serviço Social. 3ạ. ed. São Paulo: Cortez, 1995.

RAICHELIS, R. O trabalho do assistente social na esfera estatal. In: CFESS/ ABEPSS. Serviço Social: direitos sociais e competências profissionais. Brasília: CFESS/ABEPSS, UnB-CEAD. 2009.

SABADINI, M.S. Trabalho e especulação financeira: uma relação (im) perfeita. Temporalis. Brasília: ABEPSS, ano 11, n. 22, jul./dez. 2011.

SALVADOR, E. Fundo público e seguridade social no Brasil. São Paulo: Cortez, 2010a.

. Fundo público e políticas sociais na crise do capitalismo. In: Serviço Social e Sociedade. n.104, out./nov. 2010b. p. 605-632.

VIEIRA FILHO, O. Terceirização: flexibilização e utilização de mão -deobra sem vínculo empregatício - um achado para as empresas. Florianópolis: Sistema Nacional e Emprego de Santa Catarina (SINE/SC), 2006. Disponível em: <http://www.sine.sc.gov.br/diversas/arquivos/30_terceirizacao_sc_1995 _2005.pdf>. Acesso em: 12 ago. 2010.

Recebido em 01 de outubro de 2012.

Aprovado para publicação em 31 de outubro de 2012. 